\title{
The top 10 retinoblastoma research priorities in Canada as determined by patients, clinicians and researchers: a patient-oriented priority-setting partnership
}

\author{
Kaitlyn Flegg MSc, Maxwell J. Gelkopf BSc, Sarah A. Johnson PhD, Helen Dimaras PhD; for the Canadian \\ Retinoblastoma Research Advisory Board Priority Setting Steering Committee
}

\section{Abstract}

Background: Retinoblastoma is a childhood cancer of the eye that can have lifelong effects on patients and families. The purpose of this study was for people affected by retinoblastoma, clinicians and researchers to jointly determine the top 10 retinoblastoma research priorities in Canada.

\begin{abstract}
Methods: An adaptation of the James Lind Alliance Priority Setting Partnership (PSP) methodology was employed. People were invited to participate in any stage of the priority-setting process if they were a resident of Canada, and were a patient with retinoblastoma (or a family member or friend of someone diagnosed with retinoblastoma) or a clinician or researcher interested in retinoblastoma. Patients were full partners in study design and implementation, and result dissemination, through involvement in a national working group (1 patient and 9 nonpatients) and steering committee (4 patients and 11 nonpatients). In phase 1 of the study, participants responded to an online survey that asked, "What questions about retinoblastoma would you like to see answered by research?" In phase 2, the steering committee reviewed and refined the list of survey responses and decided on a list of 30 questions to be ranked by means of the nominal group technique in phase 3, a priority-setting workshop.
\end{abstract}

Results: In total, 175 retinoblastoma research questions were suggested by 59 survey participants (38 patients and 21 nonpatients). The categories with the greatest number of questions were genetics and molecular (45 [25.7\%]), second cancer (29 [16.6\%]) and psychosocial (27 [15.4\%]). The top 10 questions as ranked by the workshop participants (10 patients and 10 nonpatients) fell into 7 categories: second cancer (2 questions), follow-up (2), psychosocial (2), treatment (1), diagnosis (1), global health (1) and miscellaneous (1). The early diagnosis of retinoblastoma was identified as the top retinoblastoma research priority in Canada.

Interpretation: The list of priorities will serve as a resource for advocacy groups, research teams and funding agencies that focus on retinoblastoma. The inclusion of researchers as participants was an adaptation of the James Lind Alliance PSP methodology and enriched the research prioritization process.

Plain language summary: A national study of patients with retinoblastoma (childhood eye cancer) and their family members and friends, clinicians and researchers was conducted in Canada to answer the question "What are the top 10 retinoblastoma research priorities in Canada?" The method used was an adaptation of the James Lind Alliance Priority Setting Partnership process, commonly used in such joint priority-setting initiatives. The top priority identified related to early diagnosis of retinoblastoma. Advocacy groups, research teams and funding agencies are encouraged to align their practices with the identified retinoblastoma research priorities.

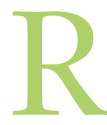
esearch priority setting identifies the research most relevant to and valued by stakeholders. This is necessary given that most funded research does not reflect the priorities of patients and clinicians, potentially reducing its impact. ${ }^{1,2}$ There are several established methods for research priority setting; the James Lind Alliance Priority Setting Partnership (PSP) method ${ }^{3}$ is arguably the most popular. The James Lind Alliance PSP method involves patients and clinicians equally in setting a top 10 list of research priorities.

Retinoblastoma is a cancer of the infant retina usually caused by a biallelic RB1 gene mutation. ${ }^{4}$ About $45 \%$ of patients with retinoblastoma have the heritable form, meaning they carry a constitutional $R B 1$ mutation that confers risk of second cancers later in life and can be passed on to offspring. Each year, 8000 children are newly diagnosed with retinoblastoma globally, about 24 of whom are in Canada. ${ }^{4}$

\section{Competing interests: None declared.}

This article has been peer reviewed.

Correspondence to: Helen Dimaras, helen.dimaras@ sickkids.ca CMAJ Open 2020. DOI:10.9778/cmajo.20190221 
The retinoblastoma research community in Canada practises patient engagement; however, a formal process to ensure equitable, diverse and sustainable inclusion was established only recently. 5 ,6 The National Retinoblastoma Patient Engagement Strategy was formed in Canada in 2016. The Canadian Retinoblastoma Research Advisory Board (CRRAB), a national multidisciplinary group composed of patients, caregivers, clinicians, researchers and other stakeholders, leads the strategy. ${ }^{5}$ The aim of the present study, was to identify the top 10 retinoblastoma research priorities in Canada, an early objective collectively agreed on by the CRRAB.

\section{Methods}

The purpose of this study was for patients with retinoblastoma, clinicians and researchers to jointly determine the top 10 retinoblastoma research priorities in Canada using an adaptation of the James Lind Alliance PSP method. We use the term "patient" to refer to people with personal experience of a health issue and their informal caregivers, including family and friends. ${ }^{7}$

\section{Working group and steering committee}

All CRRAB members were invited to participate in a working group, which led study design from December 2016 to October 2017 (Table 1). The working group recruited additional members to form the CRRAB Priority Setting Steering Committee in October 2017 (Table 1). The working group included 1 patient. When recruiting for the steering committee, we aimed to represent all stakeholder groups and encompass a range of geographic regions. The steering committee included 4 patients.

\section{Participants}

People were invited to participate in any stage of the prioritysetting process if they were a resident of Canada, and were a patient with retinoblastoma (i.e., diagnosed with retinoblastoma

\begin{tabular}{|c|c|c|c|c|c|c|}
\hline \multirow[b]{3}{*}{ Characteristic } & \multicolumn{6}{|c|}{ Group; no. (\%) of participants } \\
\hline & \multicolumn{2}{|c|}{ Working group } & \multicolumn{2}{|c|}{ Steering committee } & \multicolumn{2}{|c|}{ Workshop } \\
\hline & $\begin{array}{c}\text { Patients } \\
n=1\end{array}$ & $\begin{array}{c}\text { Nonpatients } \\
n=9\end{array}$ & $\begin{array}{c}\text { Patients } \\
n=4\end{array}$ & $\begin{array}{c}\text { Nonpatients } \\
n=11\end{array}$ & $\begin{array}{c}\text { Patients } \\
n=10\end{array}$ & $\begin{array}{c}\text { Nonpatients } \\
n=10\end{array}$ \\
\hline \multicolumn{7}{|l|}{ Sex } \\
\hline Male & $0(0)$ & $1(11)$ & $0(0)$ & $3(27)$ & $1(10)$ & $3(30)$ \\
\hline Female & $1(100)$ & $8(89)$ & $4(100)$ & $8(73)$ & $9(90)$ & $7(70)$ \\
\hline \multicolumn{7}{|l|}{ Category } \\
\hline Parent & $0(0)$ & NA & $2(50)$ & NA & $6(60)$ & NA \\
\hline Survivor & $1(100)$ & NA & $2(50)$ & NA & $4(40)$ & NA \\
\hline Clinician & NA & $3(33)$ & NA & $4(36)$ & NA & $3(30)$ \\
\hline Genetic counsellor & NA & $2(22)$ & NA & $2(18)$ & NA & $0(0)$ \\
\hline Child life specialist & NA & $0(0)$ & NA & $2(18)$ & NA & $0(0)$ \\
\hline Nurse & NA & $0(0)$ & NA & $0(0)$ & NA & $1(10)$ \\
\hline Ophthalmic imaging specialist & NA & $1(11)$ & NA & $0(0)$ & NA & $1(10)$ \\
\hline Ophthalmologist & NA & $0(0)$ & NA & $0(0)$ & NA & $1(10)$ \\
\hline Clinician-scientist & NA & $1(11)$ & NA & $3(27)$ & NA & $1(10)$ \\
\hline Ophthalmologist & NA & $1(11)$ & NA & $2(18)$ & NA & $1(10)$ \\
\hline Oncologist & NA & $0(0)$ & NA & $1(9)$ & NA & $0(0)$ \\
\hline Researcher & NA & $1(11)$ & NA & $2(18)$ & NA & $4(40)$ \\
\hline Trainee & NA & $4(44)$ & NA & $2(18)$ & NA & $2(20)$ \\
\hline \multicolumn{7}{|l|}{ Place of residence } \\
\hline Ontario & $0(0)$ & $8(89)$ & $2(50)$ & $8(73)$ & $6(60)$ & $8(80)$ \\
\hline Alberta & $0(0)$ & $1(11)$ & $1(25)$ & $2(18)$ & $3(30)$ & $1(10)$ \\
\hline British Columbia & $0(0)$ & $0(0)$ & $0(0)$ & $1(9)$ & $0(0)$ & $1(10)$ \\
\hline Other & $1(100)$ & $0(0)$ & $1(25)$ & $0(0)$ & $1(10)$ & $0(0)$ \\
\hline
\end{tabular}


or a family member or friend of someone diagnosed with retinoblastoma) or a clinician or researcher interested in retinoblastoma.

The inclusion of researchers is a noteworthy change to the James Lind Alliance PSP method, which traditionally uncovers research priorities only of patients and clinicians. ${ }^{8}$ In this method, nonclinician researchers are excluded from the priority-setting process, although they may sit on the steering committee. ${ }^{3}$ Like the James Lind Alliance, we are committed to the inclusion of patients and clinicians in setting research priorities. However, researchers have unique expertise in new research directions, study design and implementation. We also expected that having researchers present would result in accelerated uptake of the identified research priorities. ${ }^{9}$ With this in mind, we agreed that the activities in the James Lind Alliance PSP methodology could be conducted carefully alongside researchers and set out to establish an equitable process, with a 1:1 ratio of patients and nonpatients (clinicians and researchers).

\section{Design}

The study design was adapted from the 3-phase James Lind Alliance PSP method (Figure 1). The study consisted of an online survey (phase 1), an interim ranking exercise (phase 2) and an in-person priority-setting workshop (phase 3).

One deviation from the James Lind Alliance PSP method was that, as part of phase 1 , research questions were not identified through a literature search. Given the relatively small body of retinoblastoma literature, and that steering committee members have been involved in writing seminal retinoblastoma reviews ${ }^{4,10-12}$ and clinical care guidelines, ${ }^{13,14}$ participation of steering committee members as respondents in phase 1 ensured that questions identified in the current retinoblastoma literature were put forward for consideration in phase 2 .

\section{Phase 1: online survey}

Drawing from other publicly available James Lind Alliance PSP surveys, the working group developed and tested a survey using REDCap tools for electronic data capture hosted at The Hospital for Sick Children, Toronto. ${ }^{15}$ The voluntary, open online survey was available on the senior author's (H.D.) laboratory website from Oct. 3 to Nov. 12, 2017. We intended to offer the survey online for no less than 1 month; the final survey duration was dictated by pragmatic considerations including research ethics board and administrative timelines, steering committee meetings and workshop scheduling.

A convenience sample was recruited. Members of the CRRAB shared recruitment materials in their eye clinics and on social media, and existing networks such as the Canadian Retinoblastoma Research Registry, the Canadian National Retinoblastoma Tumor Board and the Canadian Association of Genetic Counsellors shared the materials widely (Appendix 1, available at www.cmajopen.ca/content/8/2/E420/suppl/DC1). Snowball sampling was encouraged among the CRRAB community.

After providing implied informed consent, participants provided their demographic information on the first page of the survey (using adaptive questioning, where "prefer not to say" options were offered). The second page of the survey then asked, "What questions about retinoblastoma would you like to see answered by research?"

Survey responses were processed by K.F. and H.D. as follows. Submissions were screened for duplicate entries based on question topic and respondent identifiers (i.e., participant

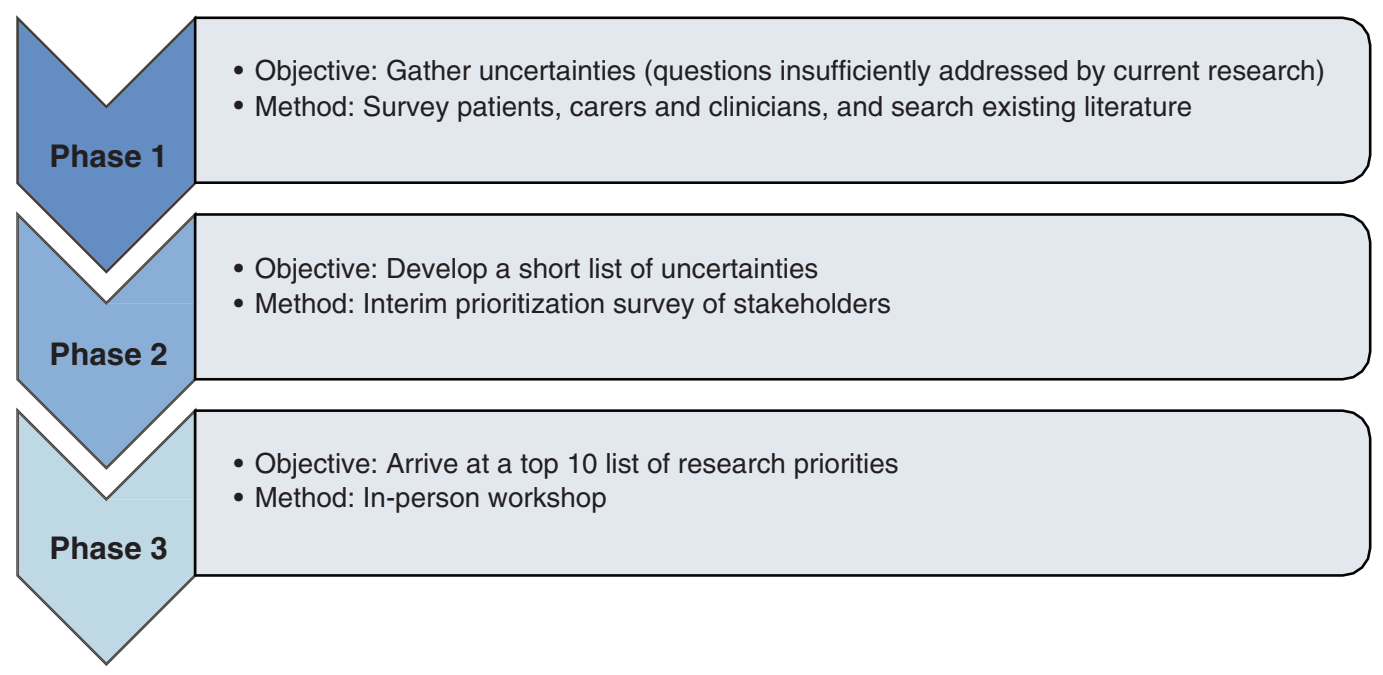

Figure 1: Overview of James Lind Alliance Priority Setting Partnership method. 
name, email address) and then categorized according to a coding taxonomy developed by H.D. and K.F.: awareness, diagnosis, family planning, follow-up, genetics and molecular, global health, psychosocial, second cancer, treatment, trilateral retinoblastoma, vision and miscellaneous. When a single submission included more than 1 question, the individual questions were separated and reworded (with narrative text removed, if applicable) to result in concise questions. Duplicate questions were combined, questions that were out of scope were removed, and questions known to be answered by existing systematic reviews, clinical care guidelines or individual studies were removed.

\section{Phase 2: steering committee interim ranking}

The steering committee reviewed the phase 1 results and completed a second round of processing to produce a refined list of questions. During this processing, based on their respective areas of expertise, members of the steering committee were asked to identify any questions that were answered by existing systematic reviews, clinical care guidelines or individual studies. Such questions were reviewed by the steering committee and removed if consensus was reached on removal. The steering committee then conducted an interim ranking of the refined list of questions.

Since the steering committee had an imbalance of patient to nonpatient members (4:11), to ensure fair weighting, a steering committee patient rank and a steering committee nonpatient rank were calculated individually and then combined to produce an adjusted steering committee interim ranking. By consensus, the steering committee decided on a list of 30 questions to be ranked at the priority-setting workshop.

\section{Phase 3: priority-setting workshop}

The priority-setting workshop, held on Dec. 9, 2017, followed the established process. ${ }^{3}$ A chairperson with experience facilitating other priority-setting workshops was hired to lead the workshop with 2 facilitators (K.F., M.G.). The steering committee was committed to an equitable workshop, employing the nominal group technique to include diverse perspectives, with a 1:1 ratio of patients to nonpatients.

Participants were separated into 3 facilitator-led groups with representation from patients and nonpatients. Each group had a set of 30 cards displaying a question and contextual information from the online survey (e.g., frequency, quotes). Using the cards, each group organized the questions from highest to lowest priority. An aggregate ranking was computed by the chairperson and facilitators, using the individual group rankings, and presented to all participants. Participants were then assigned to 3 new groups with representation from patients and nonpatients, again led by a facilitator. The first aggregate ranking was reviewed and revised by each group. Groups noted their revised ranking, and this was used to compute a second aggregate ranking. The chairperson led all participants in a review of the second aggregate ranking. Ties and suggested refinements were discussed and agreed on by a vote, with a majority needed to break a tie or adopt a refinement.

\section{Patient engagement}

The study was designed collaboratively by the working group during 8 video-conference meetings. The survey results were processed by the steering committee during 2 videoconference meetings. Where requested, one-on-one meetings were coordinated with patient partners in the working group and on the steering committee to provide additional support and to accommodate scheduling conflicts. Patients involved in the workshop were offered modest travel stipends. All members of the working group and steering committee were invited to provide feedback on the manuscript, which was coauthored by a patient partner (S.A.J., the patient in the working group). At The Hospital for Sick Children, a parentin-research role was created on the senior author's research team. ${ }^{16}$ This person, alongside members of CRRAB, is leading a national knowledge translation project disseminating the findings of this study.

\section{Statistical analysis}

We used summary statistics to characterize the online survey participants.

\section{Ethics approval}

Research ethics board approval was obtained from The Hospital for Sick Children.

\section{Results}

\section{Phase 1: online survey}

Online surveys were completed by 59 people, 38 patients (64\%) and 21 nonpatients (36\%) (Table 2).

Respondents were primarily female (50 [85\%]) and Ontario residents $(34[58 \%])$. Patients were parents $(28[74 \%])$ or survivors (10 [26\%]); the mean patient age was 38 (standard deviation 8 ) years. Most patients (26 [68\%]) had bilateral retinoblastoma. Nonpatients were clinicians (16 [76\%]), clinicianscientists (3 [14\%]) or researchers (2 [10\%]).

In total, 175 questions were suggested (Table 3). The categories with the greatest number of questions were genetics and molecular (45 [25.7\%]), second cancer (29 [16.6\%]) and psychosocial (27 [15.4\%]). Questions most commonly suggested by patients were genetics and molecular (31/114 [27.2\%]), second cancer (22/114 [19.3\%]) and psychosocial (15/114 [13.2\%]). Questions most commonly suggested by nonpatients were treatment $(15 / 61[25 \%])$, genetics and molecular (14/61 [23\%]) and psychosocial (12/61 [20\%]). All questions concerning awareness and vision were suggested by patients, whereas all questions concerning global health and most $(15 / 21[71 \%])$ of those concerning treatment were suggested by nonpatients. After survey responses were processed, 46 questions were removed (Figure 2), resulting in 129 questions across all 12 categories that were presented to the steering committee.

\section{Phase 2: steering committee interim ranking}

The steering committee generated a refined list of 96 questions subject to steering committee ranking (Figure 2). The 
Table 2: Demographic characteristics of online survey respondents

\begin{tabular}{|c|c|c|}
\hline \multirow[b]{2}{*}{ Characteristic } & \multicolumn{2}{|c|}{ No. $(\%)$ of respondents* } \\
\hline & $\begin{array}{c}\text { Patients } \\
n=38\end{array}$ & $\begin{array}{c}\text { Nonpatients } \\
\quad n=21\end{array}$ \\
\hline Age, yr, mean $\pm S D$ & $38 \pm 8$ & $46 \pm 9 \dagger$ \\
\hline \multicolumn{3}{|l|}{ Sex } \\
\hline Female & $34(89)$ & $16(76)$ \\
\hline Male & $4(11)$ & $5(24)$ \\
\hline \multicolumn{3}{|l|}{ Category } \\
\hline Parent & $24(63)$ & NA \\
\hline Parent and survivor & $2(5)$ & NA \\
\hline Survivor & $8(21)$ & NA \\
\hline Parent and spouse of survivor & $2(5)$ & NA \\
\hline Family & $1(3)$ & NA \\
\hline $\begin{array}{l}\text { Unaffected RB1 mutation carrier } \\
\text { and parent }\end{array}$ & $1(3)$ & NA \\
\hline Clinician & NA & $16(76)$ \\
\hline Ophthalmologist & NA & $5(24)$ \\
\hline Oncologist & NA & $4(19)$ \\
\hline Genetic counsellor & NA & $3(14)$ \\
\hline Child life specialist & NA & $2(10)$ \\
\hline Molecular geneticist & NA & $1(5)$ \\
\hline Social worker & NA & $1(5)$ \\
\hline Clinician-scientist & NA & $3(14)$ \\
\hline Ophthalmologist & NA & $2(10)$ \\
\hline Medical geneticist & NA & $1(5)$ \\
\hline Researcher & NA & $2(10)$ \\
\hline \multicolumn{3}{|l|}{ Laterality } \\
\hline Bilateral & $26(68)$ & NA \\
\hline Unilateral & $11(29)$ & NA \\
\hline Not provided & $1(3)$ & NA \\
\hline \multicolumn{3}{|l|}{ Place of residence } \\
\hline Ontario & $22(58)$ & $12(57)$ \\
\hline Alberta & $11(29)$ & $2(10)$ \\
\hline New Brunswick & $1(3)$ & $0(0)$ \\
\hline Quebec & $1(3)$ & $3(14)$ \\
\hline Nova Scotia & $0(0)$ & $2(10)$ \\
\hline Not provided & $3(8)$ & $2(10)$ \\
\hline $\begin{array}{l}\text { Note: } \mathrm{NA}=\text { not applicable, } \mathrm{SD}=\text { standard } \mathrm{c} \\
{ }^{*} \text { Except where noted otherwise. } \\
\dagger n=20 \text {. }\end{array}$ & & \\
\hline
\end{tabular}

30 questions ranked by the steering committee as having the highest research priority and 9 additional questions that fell outside the top 30 but were suggested by more than 1 survey respondent were further considered by the steering committee for the priority-setting workshop. A final list of 30 questions was agreed on by the steering committee for consideration at the workshop. Questions from all categories except trilateral retinoblastoma were included in the final list.

\section{Phase 3: priority-setting workshop}

There were 20 workshop participants, 10 patients and 10 nonpatients (Table 1). All patients were affected by heritable retinoblastoma. Parents participating included those with young children currently undergoing retinoblastoma treatment and parents of adult survivors.

There were similarities in the first and second aggregate rankings (Table 4). Six of the top 10 questions in the second aggregate ranking were also in the top 10 in the first aggregate ranking. Similarly, 6 of the bottom 10 questions in the second aggregate ranking were also in the bottom 10 in the first aggregate ranking. For the final ranking, 4 ties in the second aggregate ranking were decided by vote. Four additional questions were reorganized in response to suggestions of the group.

The top-ranking question was how to increase early diagnosis of retinoblastoma (Table 4). No question from the awareness, family planning, genetics and molecular, or vision categories ranked among the top 10 .

\section{Interpretation}

This study brought together patients affected by retinoblastoma, clinicians and researchers to jointly identify the top 10 retinoblastoma research priorities in Canada. The top research priority identified was how to increase early diagnosis of retinoblastoma. Four of the top 10 research priorities addressed second cancer or follow-up, 2 addressed psychosocial considerations, 1 addressed retinoblastoma treatment, 1 was concerned with how to provide a detailed pathway of care to patients with retinoblastoma and their families, and 1 (the 10th-highest priority) was concerned with how optimal retinoblastoma care can be delivered in low-resource settings.

Early diagnosis of retinoblastoma increases the possibility of favourable outcomes (vision and survival). ${ }^{13}$ In its position statement, the Canadian Paediatric Society recommends dilated eye examinations for children, including inspection of the red reflex, when newborn to 3 months of age, and at 6-12 months of age. ${ }^{17}$ Failure of visualization or abnormalities of the reflex are indications for urgent referral to an ophthalmologist. ${ }^{17}$ Yet the mean age at retinoblastoma diagnosis in Canada is 27 months for unilateral disease and 15 months for bilateral disease. ${ }^{10}$ This suggests that there is poor adherence to current vision screening guidelines, or the guidelines are insufficient for detecting retinoblastoma given the variable timing and topography of tumour development in the infant retina.

There is a paucity of reliable information about second cancer risk for the more recent cohort of survivors of heritable retinoblastoma, who have received new types of first-line therapy, including intra-arterial chemotherapy. ${ }^{18}$ Consequentially, no standardized plan exists for adult follow-up of heritable retinoblastoma survivors. 
Table 3: Number of questions from online survey (phase 1) and number presented to the steering committee, by category

\begin{tabular}{|c|c|c|c|c|c|c|c|c|c|c|}
\hline \multirow[b]{3}{*}{ Category } & \multicolumn{6}{|c|}{ Questions from survey } & & & & \multirow{3}{*}{$\begin{array}{l}\text { No. }(\%) \text { of } \\
\text { questions } \\
\text { presented to } \\
\text { steering } \\
\text { committee }\end{array}$} \\
\hline & \multirow[b]{2}{*}{$\begin{array}{c}\text { No. }(\%) \\
\text { suggested by } \\
\text { patients }\end{array}$} & \multicolumn{4}{|c|}{ No. (\%) suggested by nonpatients } & \multirow[b]{2}{*}{$\begin{array}{l}\text { Overall } \\
\text { total }\end{array}$} & \multicolumn{3}{|c|}{ Questions removed } & \\
\hline & & Clinicians & $\begin{array}{l}\text { Clinician- } \\
\text { scientists }\end{array}$ & Researchers & Total & & $\begin{array}{l}\text { Out of } \\
\text { scope }\end{array}$ & $\begin{array}{l}\text { Already } \\
\text { answered } \\
\text { by research }\end{array}$ & Duplicate & \\
\hline Awareness & $4(3.5)$ & 0 & 0 & 0 & $0(0)$ & $4(2.3)$ & 1 & 0 & 0 & $3(2.3)$ \\
\hline Diagnosis & $9(7.9)$ & 4 & 0 & 0 & $4(7)$ & $13(7.4)$ & 0 & 0 & 4 & $9(7.0)$ \\
\hline Family planning & $7(6.1)$ & 1 & 0 & 0 & $1(2)$ & $8(4.6)$ & 1 & 2 & 0 & $5(3.9)$ \\
\hline Follow-up & $9(7.9)$ & 1 & 1 & 0 & $2(3)$ & $11(6.3)$ & 0 & 0 & 0 & $11(8.5)$ \\
\hline $\begin{array}{l}\text { Genetics and } \\
\text { molecular }\end{array}$ & $31(27.2)$ & 3 & 4 & 7 & $14(23)$ & $45(25.7)$ & 6 & 3 & 8 & $28(21.7)$ \\
\hline Global health & $0(0.0)$ & 2 & 0 & 1 & $3(5)$ & $3(1.7)$ & 0 & 0 & 0 & $3(2.3)$ \\
\hline Psychosocial & $15(13.2)$ & 11 & 0 & 1 & $12(20)$ & $27(15.4)$ & 0 & 0 & 3 & $24(18.6)$ \\
\hline Second cancer & $22(19.3)$ & 6 & 1 & 0 & $7(11)$ & $29(16.6)$ & 0 & 1 & 9 & $19(14.7)$ \\
\hline Treatment & $6(5.3)$ & 14 & 1 & 0 & $15(25)$ & $21(12.0)$ & 3 & 0 & 4 & $14(10.8)$ \\
\hline $\begin{array}{l}\text { Trilateral } \\
\text { retinoblastoma }\end{array}$ & $2(1.8)$ & 1 & 0 & 0 & $1(2)$ & $3(1.7)$ & 0 & 1 & 0 & $2(1.6)$ \\
\hline Vision & $7(6.1)$ & 0 & 0 & 0 & $0(0)$ & $7(4.0)$ & 0 & 0 & 0 & $7(5.4)$ \\
\hline Miscellaneous & $2(1.8)$ & 2 & 0 & 0 & $2(3)$ & $4(2.3)$ & 0 & 0 & 0 & $4(3.1)$ \\
\hline Total & $114(65.1)$ & 45 & 7 & 9 & $61(35)$ & $175(100.0)$ & 11 & 7 & 28 & $129(100.0)$ \\
\hline
\end{tabular}

There are discordant findings about the psychosocial wellbeing of patients with retinoblastoma, and these outcomes have yet to be examined in Canada. ${ }^{19-23}$

The fact that only 1 of the 10 top research priorities addressed retinoblastoma treatment is likely a consequence of the survival rate in Canada: more than $95 \%$ of children with retinoblastoma survive, with favourable outcomes. ${ }^{13}$

The research priority regarding how to provide a detailed pathway of care to patients with retinoblastoma and their families aligns with growing evidence that supports patient-centred care ${ }^{24}$ and may have been partly motivated by plans to deploy DEPICT HEALTH, a point-of-care retinoblastoma database, globally. ${ }^{25}$

The priority concerned with how optimal retinoblastoma care can be delivered in low-resource settings was the only priority in the top 10 suggested by a researcher alone. This supports our assertion that there is value in including researchers in research-prioritization exercises.

Notably, although genetics and molecular questions were suggested in the survey more often than any other category, the top 10 research priorities did not include a question from this category. The proportion of genetics and molecular questions suggested in the survey may not reflect their relative importance. Rather, our research has shown that patients have challenges accessing information about and understanding retinoblastoma genetics and thus, may have developed more questions in this domain. ${ }^{26}$

To our knowledge, the only other research-prioritysetting endeavour that mentioned retinoblastoma was the UK Sight Loss and Vision PSP. ${ }^{27}$ As part of that study, research questions for childhood-onset eye disorders were prioritized, and the question ranked eighth was "How can retinoblastoma be identified, prevented and treated in children?"

\section{Limitations}

Our study has limitations that warrant consideration. Patient survey participants may not have been representative of the broader Canadian retinoblastoma community. Only 38 patients participated in the survey, largely female parents from Ontario. Similarly, the majority of patient participants in the workshop (and to a lesser extent, the survey) were affected by heritable retinoblastoma. Given the lifelong implications of the disease, it is not surprising that those with heritable retinoblastoma are particularly incentivized to participate in research. This imbalance may have biased the study results toward survivorship and long-term effects of retinoblastoma.

Two additional deviations from the customary James Lind Alliance PSP method are important to note. First, in phase 1, we were precluded from using only systematic reviews and guidelines to verify that the questions were unanswered; this approach is particularly relevant when a James Lind Alliance PSP is identifying unanswered research questions about disease diagnosis or treatment. Given the broad scope of retinoblastoma research questions being prioritized and the familiarity of the steering committee with the limited number of retinoblastoma systematic reviews (i.e., 1 Cochrane review) and guidelines, we felt it prudent that the steering committee verify whether questions were unanswered using their full breadth of knowledge. Second, when the questions were reworded in phase 1 of the study, the PICO (patient or population, intervention, comparator or control, and outcome) structure was not adopted consistently. Feedback from the 


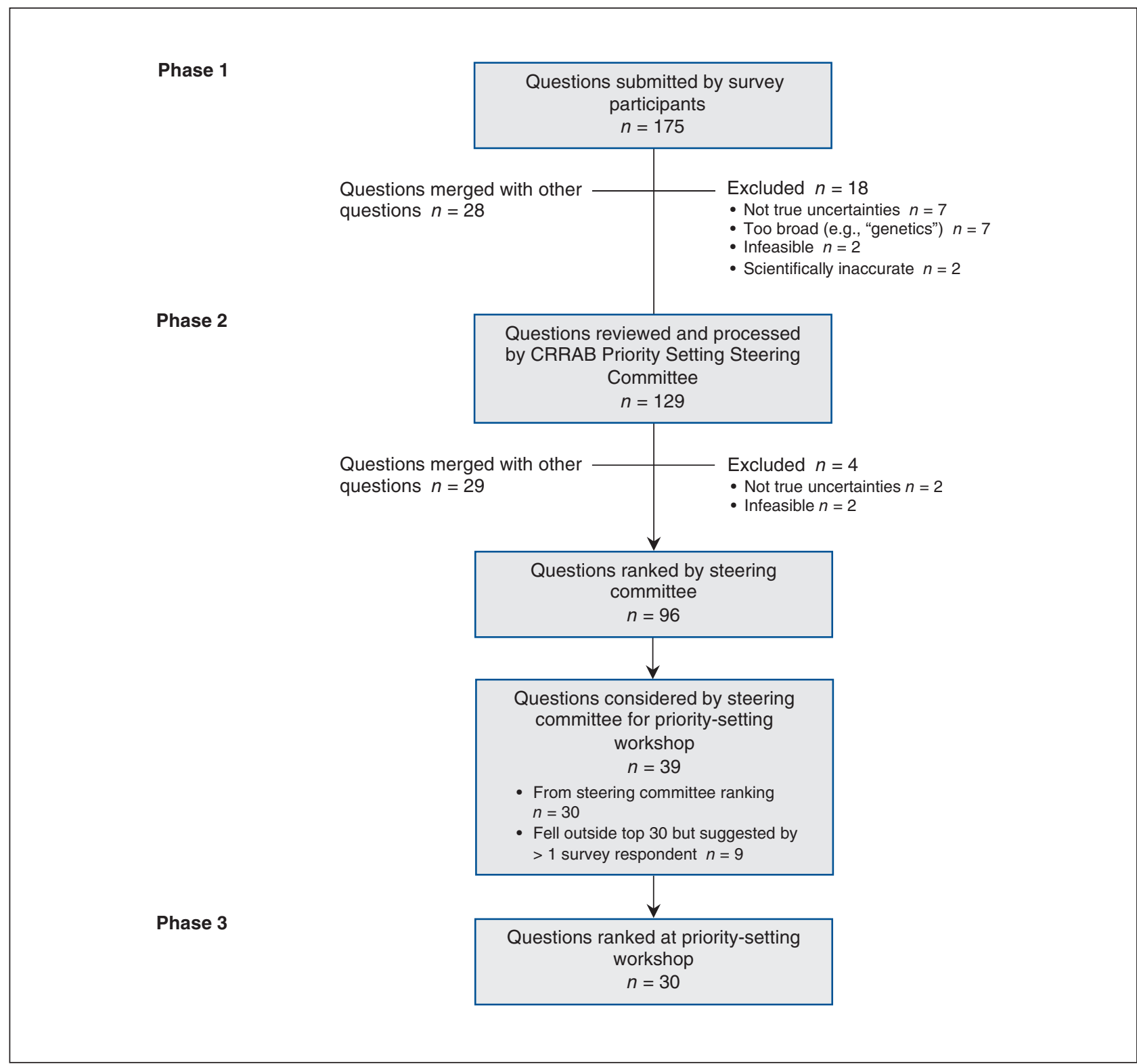

Figure 2: Flow diagram showing priority-setting process for retinoblastoma research. Note: CRRAB = Canadian Retinoblastoma Research Advisory Board.

workshop participants suggested that they would have valued the opportunity to participate in the question wording or have an orientation to each question with an outline of the meaning and relevant background.

\section{Lessons learned from patient engagement}

The CRRAB $^{5}$ promotes research that meets the Canadian Institutes of Health Research's definition of successful patient engagement. ${ }^{7}$ By design, this study valued experiential knowledge as evidence. We partnered with patients in a range of roles including leadership opportunities, working as true partners toward a shared goal. Opportunities to develop capacities of all stakeholders in a safe environment of mutual respect were offered informally. This collaborative approach was reinforced by feedback from previous patient partners. ${ }^{16}$
We have commented elsewhere on our challenges with patient-oriented research. ${ }^{16,28}$ Funders seldom support nonresearch activities necessary for sustainable patient-oriented research (e.g., establishing a social media presence, maintaining registries), which is taxing on researchers and patient partner volunteers. Travel reimbursements and stipends for patient partners are embedded in all of the senior author's research grants, yet it is difficult to include these costs in smaller grants, and, these are not always allowable costs. One approach to addressing these issues is the paid Parent in Research role within the senior author's research team, ${ }^{16}$ which was funded initially by a 1-year Canadian Institutes of Health Research Strategy for Patient-Oriented Research Collaboration grant. Establishing fixed funding for this role is a challenge. 


\begin{tabular}{|c|c|c|c|c|}
\hline \multirow{2}{*}{$\begin{array}{l}\text { Final } \\
\text { rank }\end{array}$} & \multirow[b]{2}{*}{ Category } & \multirow[b]{2}{*}{ Question } & \multicolumn{2}{|c|}{ Aggregate ranking } \\
\hline & & & First & Second \\
\hline 1 & Diagnosis & How to increase early diagnosis of retinoblastoma (i.e., decrease age or stage at diagnosis)? & 7 & 1 \\
\hline 2 & Second cancer & $\begin{array}{l}\text { What second cancer screening is optimal for heritable retinoblastoma survivors (including } \\
\text { whole body magnetic resonance imaging)? }\end{array}$ & 1 & 1 \\
\hline 3 & Psychosocial & $\begin{array}{l}\text { How to provide culturally competent social, emotional and psychological support to patients } \\
\text { with retinoblastoma, survivors, parents and families (at diagnosis and beyond)? }\end{array}$ & 2 & 2 \\
\hline 4 & Follow-up & $\begin{array}{l}\text { What is the optimal follow-up (including ophthalmologic and oncologic) for patients with } \\
\text { heritable retinoblastoma and survivors (by diagnosis and treatment), and how can we ensure } \\
\text { this is provided to all? }\end{array}$ & 9 & 3 \\
\hline 5 & Treatment & Prospective retinoblastoma treatment studies with long-term follow-up & 5 & 4 \\
\hline 6 & Psychosocial & What is the effect of enucleation and vision loss on retinoblastoma survivors? & 11 & 5 \\
\hline 7 & Second cancer & $\begin{array}{l}\text { What are the risk factors for second cancers in heritable retinoblastoma survivors, and, in turn, } \\
\text { what do heritable retinoblastoma survivors need to know about living well and minimizing risk of } \\
\text { second cancers? }\end{array}$ & 7 & 6 \\
\hline 8 & Miscellaneous & $\begin{array}{l}\text { How to improve collaboration across the different top centres caring for retinoblastoma: forming } \\
\text { an international consortium, a unified registry and combined trials, instead of the current air of } \\
\text { competition? }\end{array}$ & 17 & 10 \\
\hline 9 & Follow-up & $\begin{array}{l}\text { How to provide a detailed pathway of care or plan, outlining treatment and follow-up, to } \\
\text { patients with retinoblastoma and families? }\end{array}$ & 13 & 8 \\
\hline 10 & Global health & $\begin{array}{l}\text { How can optimal retinoblastoma care be delivered in low-resource settings (including rural and } \\
\text { remote communities)? }\end{array}$ & 4 & 9 \\
\hline 11 & Treatment & $\begin{array}{l}\text { Clinical trials of novel agents, targeted agents added to "backbone" chemotherapy or } \\
\text { intra-arterial chemotherapy to improve eye-salvage rates }\end{array}$ & 3 & 9 \\
\hline 12 & $\begin{array}{l}\text { Genetics and } \\
\text { molecular }\end{array}$ & What genetic mechanism results in second cancers in heritable retinoblastoma survivors? & 10 & 7 \\
\hline 13 & Treatment & Better identification of who needs chemotherapy after high-risk pathologic findings & 12 & 10 \\
\hline 14 & Diagnosis & $\begin{array}{l}\text { What new technology could be used to diagnose retinoblastoma earlier, including noninvasive } \\
\text { in utero testing? }\end{array}$ & 6 & 11 \\
\hline 15 & Awareness & $\begin{array}{l}\text { How to increase family doctor/pediatrician awareness of retinoblastoma (i.e., signs and } \\
\text { symptoms, and the importance of early diagnosis), and screening and diagnosis of } \\
\text { retinoblastoma? }\end{array}$ & 6 & 12 \\
\hline 16 & Psychosocial & $\begin{array}{l}\text { How can we help families cope better during diagnosis and critical stages (including } \\
\text { enucleation)? }\end{array}$ & 8 & 13 \\
\hline 17 & Second cancer & $\begin{array}{l}\text { What are the risks of second cancers for mosaic } R B 1 \text { mutation carriers (i.e., those in whom } \\
\text { RB1 mutation is present in some but not all cells in their body)? }\end{array}$ & 18 & 14 \\
\hline 18 & Treatment & How to reduce side [adverse] effects from retinoblastoma treatments? & 12 & 15 \\
\hline 19 & $\begin{array}{l}\text { Genetics and } \\
\text { molecular }\end{array}$ & $\begin{array}{l}\text { Can we identify the key molecular event that distinguishes retinoma (benign retinoblastoma } \\
\text { precursor) from retinoblastoma? }\end{array}$ & 16 & 16 \\
\hline 20 & $\begin{array}{l}\text { Genetics and } \\
\text { molecular }\end{array}$ & Can a known $R B 1$ gene mutation be corrected? & 15 & 18 \\
\hline 21 & Follow-up & $\begin{array}{l}\text { How to improve the sensitivity of minimal residual disease (i.e., metastasized cancer cells that } \\
\text { cannot be detected by routine tests) diagnostics in retinoblastoma? }\end{array}$ & 20 & 17 \\
\hline 22 & $\begin{array}{l}\text { Genetics and } \\
\text { molecular }\end{array}$ & $\begin{array}{l}\text { How to communicate with and educate patients, survivors and parents about retinoblastoma } \\
\text { genetics and their specific retinoblastoma genetic testing results (including new tools, } \\
\text { techniques and innovations)? }\end{array}$ & 16 & 19 \\
\hline 23 & Family planning & $\begin{array}{l}\text { What is the best way to support and educate heritable retinoblastoma survivors before they } \\
\text { have their own children and to ensure their children have optimal perinatal care? }\end{array}$ & 14 & 20 \\
\hline 24 & $\begin{array}{l}\text { Genetics and } \\
\text { molecular }\end{array}$ & How can second cancers be prevented in heritable retinoblastoma survivors? & 13 & 21 \\
\hline 25 & Second cancer & What is the second cancer incidence among heritable retinoblastoma survivors? & 18 & 22 \\
\hline 26 & $\begin{array}{l}\text { Genetics and } \\
\text { molecular }\end{array}$ & How can we reduce the risk of second cancers in heritable retinoblastoma survivors? & 19 & 22 \\
\hline 27 & Psychosocial & $\begin{array}{l}\text { What social, emotional and psychologic support services are available across Canada for } \\
\text { patients with retinoblastoma, survivors and parents (i.e., comparisons nationally)? }\end{array}$ & 21 & 23 \\
\hline 28 & Psychosocial & $\begin{array}{l}\text { What is the impact — on mental health, finances, employment, siblings and family life - when } \\
\text { one must travel long distances for retinoblastoma care? }\end{array}$ & 22 & 24 \\
\hline 29 & Vision & $\begin{array}{l}\text { How can scar tissue/calcium in the eye from retinoblastoma treatment be removed to give better } \\
\text { vision? }\end{array}$ & 23 & 25 \\
\hline 30 & $\begin{array}{l}\text { Genetics and } \\
\text { molecular }\end{array}$ & What causes heritable (germline) and nonheritable (somatic) retinoblastoma mutations? & 24 & 26 \\
\hline
\end{tabular}




\section{Conclusion}

We achieved consensus on the top 10 retinoblastoma research priorities in Canada using an adaptation of the James Lind Alliance PSP method. These results are intended to align the retinoblastoma research agenda in Canada to the collective values of patients, clinicians and researchers. By galvanizing research that all stakeholders buy into, the top 10 retinoblastoma research priorities can enhance the quality of retinoblastoma research results and accelerate uptake into practice. Our modification - to include researchers as participants - was a valuable element in identifying a research priority that was subsequently ranked in the top 10 by all participants. By sharing the final research priorities broadly, we expect that the top 10 list will serve as a resource for advocacy groups, research teams and funding agencies that focus on retinoblastoma.

\section{References}

1. Crowe S, Fenton M, Hall M, et al. Patients', clinicians' and the research communities' priorities for treatment research: there is an important mismatch [published erratum in Res Involv Engagem 2015;1:2]. Res Involv Engagem 2015;1:14.

2. Tallon D, Chard J, Dieppe P. Relation between agendas of the research community and the research consumer. Lancet 2000;355:2037-40.

3. The James Lind Alliance Guidebook: version 7. London (UK): National Institute for Health Research; 2018. Available: www.jla.nihr.ac.uk/jla-guidebook/ downloads/Print-JLA-guidebook-version-7-March-2018.pdf (accessed 2020 Apr. 28).

4. Dimaras H, Corson TW, Cobrinik D, et al. Retinoblastoma. Nat Rev Dis Primers 2015;1:15021.

5. Gelkopf MJ, Avramov I, Baddeliyanage R, et al. The Canadian Retinoblastoma Research Advisory Board: a framework for patient engagement. Res Involv Engagem 2020;6:7.

6. Skilton AM, Low LG, Dimaras H. Patients, public and service users are experts by experience: an overview from ophthalmology research in Canada, UK and beyond. Ophthalmol Ther 2020 Feb. 29 [Epub ahead of print]. doi: 10.1007/s40123-020-00237-x.

7. Strategy for Patient-Oriented Research (SPOR): overview. Ottawa: Canadian Institutes of Health Research. Available: www.cihr-irsc.gc.ca/e/documents/ fact_sheet_spor_overview_e.pdf (accessed 2020 Apr. 28).

8. Chalmers I, Atkinson P, Fenton M, et al. Tackling treatment uncertainties together: the evolution of the James Lind Initiative, 2003-2013. 7 R Soc Med 2013;106:482-91.

9. Buckley BS, Grant AM, Glazener CM. Case study: a patient-clinician collaboration that identified and prioritized evidence gaps and stimulated research development. 7 Clin Epidemiol 2013;66:483-9.

10. Dimaras H, Kimani K, Dimba EA, et al. Retinoblastoma. Lancet 2012;379:1436-46.

11. Yousef YA, Soliman SE, Astudillo PP, et al. Intra-arterial chemotherapy for retinoblastoma: a systematic review. 7AMA Ophthalmol 2016;134:584-91.

12. Dimaras H, Corson TW. Retinoblastoma, the visible CNS tumor: a review. 7 Neurosci Res 2019;97:29-44.

13. Canadian Retinoblastoma Society. National Retinoblastoma Strategy Canadian Guidelines for Care: Stratégie thérapeutique du rétinoblastome guide clinique canadien. Can 7 Ophthalmol 2009;44(Suppl 2):S1-88.

14. Retinoblastoma: best practice guidelines 2014 - Kenya National Retinoblastoma Strategy. Nairobi: Kenyan Ministry of Health. Available: http://guidelines.health. go.ke:8000/media/Best-Practice-Retinoblastoma_September-2014.pdf (accessed 2020 Apr. 28).

15. Harris PA, Taylor R, Thielke R, et al. Research electronic data capture (REDCap) - a metadata-driven methodology and workflow process for providing translational research informatics support. 7 Biomed Inform 2009; 42:377-81.

16. White E, Baddeliyanage $\mathrm{R}$, Shaikh F, et al. Meaningful patient engagement in research: lessons from retinoblastoma. Pediatrics 2019;143:e20182166.

17. Vision screening in infants, children and youth. Paediatr Child Health 2009;14: 246-51.
18. Kletke SN, Soliman SE, Gallie BL. Radiation compromised survival of patients with heritable retinoblastoma (H1): What will be the long-term consequences of current eye salvage therapies? Ann Eye Sci 2017;2:26.

19. van Dijk J, Huisman J, Moll AC, et al. Health-related quality of life of child and adolescent retinoblastoma survivors in the Netherlands. Health Qual Life Outcomes 2007;5:65.

20. van Dijk J, Imhof SM, Moll AC, et al. Quality of life of adult retinoblastoma survivors in the Netherlands. Health Qual Life Outcomes 2007;5:30.

21. Batra A, Kumari M, Paul R, et al. Quality of life assessment in retinoblastoma: a cross-sectional study of 122 survivors from India. Pediatr Blood Cancer 2016; 63:313-7.

22. Weintraub N, Rot I, Shoshani N, et al. Participation in daily activities and quality of life in survivors of retinoblastoma. Pediatr Blood Cancer 2011;56: 590-4.

23. Ford JS, Chou JF, Sklar CA, et al. Psychosocial outcomes in adult survivors of retinoblastoma. 7 Clin Oncol 2015;33:3608-14.

24. Ricciardi L, Mostashari F, Murphy J, et al. A national action plan to support consumer engagement via e-health. Health Aff (Millwood) 2013;32:376-84.

25. Gallie B, Houghham K, Truong T, et al. Enhancing communication about retinoblastoma clinical encounters using a novel global data repository [abstract]. Pediatr Blood Cancer 2017;64(Suppl 3):e26772.

26. Hill JA, Gedleh A, Lee S, et al. Knowledge, experiences and attitudes concerning genetics among retinoblastoma survivors and parents. Eur 7 Hum Genet 2018;26:505-17.

27. Rowe F, Wormald R, Cable R, et al. The Sight Loss and Vision Priority Setting Partnership (SLV-PSP): overview and results of the research prioritisation survey process. BM7 Open 2014;4:e004905.

28. Moses C, Flegg K, Dimaras H. Patient knowledge, experiences and preferences regarding retinoblastoma and research: a qualitative study. Health Expect 2020 Feb. 29 [Epub ahead of print]. doi: 10.1111/hex.13043.

Affiliations: Department of Ophthalmology and Vision Sciences (Flegg, Gelkopf, Dimaras), The Hospital for Sick Children, Toronto, Ont.; Department of Neuroscience (Johnson), Evelyn F. and William L. McKnight Brain Institute, University of Florida, Gainesville, Fla.; Department of Ophthalmology and Vision Sciences (Dimaras), Faculty of Medicine, and Division of Clinical Public Health (Dimaras), Dalla Lana School of Public Health, University of Toronto; Child Health Evaluative Sciences Program (Dimaras) and Centre for Global Child Health (Dimaras), SickKids Research Institute, Toronto, Ont.

Contributors: Kaitlyn Flegg and Helen Dimaras conceptualized and designed the study and interpreted the data. Maxwell Gelkopf and Sarah Johnson assisted with the study design. Kaitlyn Flegg and Maxwell Gelkopf collected the data. Helen Dimaras supervised data collection and analysis. Kaitlyn Flegg analyzed the data and drafted the manuscript. Maxwell Gelkopf, Sarah Johnson and Helen Dimaras revised the manuscript critically for important intellectual content. All of the authors approved the final version to be submitted and agreed to be accountable for all aspects of the work.

Funding: This work was supported by the SickKids Garron Family Cancer Center Conference Fund, and by Meeting, Planning and Dissemination grant 152652 from the Institute of Cancer Research, Canadian Institutes of Health Research.

Data sharing: Aggregate data may be accessed for relevant research ethics board approved research by emailing the corresponding author, Helen Dimaras, helen.dimaras@sickkids.ca.

Acknowledgements: The authors acknowledge the participants in the working group, the Canadian Retinoblastoma Research Advisory Board Priority Setting Steering Committee and the priority-setting workshop, and Dr. Karen Born, who served as the workshop chairperson.

Supplemental information: For reviewer comments and the original submission of this manuscript, please see www.cmajopen.ca/content/8/2/ E420/suppl/DC1. 